\title{
Understanding hemodynamics with seven variables
}

\author{
Dimitri Gusmao-Flores ${ }^{1,2,3} \wedge$, Mariana Luz ${ }^{1,2}$, Bruna Brandao Barreto ${ }^{1,2} \wedge$ \\ ${ }^{1}$ Intensive Care Unit, Hospital da Mulher, Salvador, Bahia, Brazil; ${ }^{2}$ Programa de Pós Graduação em Medicina e Saúde, Faculdade de Medicina da \\ Bahia, Universidade Federal da Bahia, Salvador, Bahia, Brazil; ${ }^{3}$ Intensive Care Unit, Hospital da Cidade, Salvador, Bahia, Brazil \\ Correspondence to: Dimitri Gusmao-Flores. Prof. Sabino Silva, 273 Ap 801, 40255-150, Salvador, Bahia, Brazil. Email: dimitrigusmao@gmail.com.
}

Submitted Jul 24, 2020. Accepted for publication Sep 06, 2020.

doi: $10.21037 /$ atm-20-5493

View this article at: http://dx.doi.org/10.21037/atm-20-5493

We read with great enthusiasm two excellent reviews on monitoring in critically ill patients, which reinforces the need to integrate different variables to better understand the hemodynamic status of patients with circulatory shock $(1,2)$. This life-threating condition was classified by Weil and Shubin, many years ago, in four types (hypovolemic, cardiogenic, obstructive and distributive) considering different pathophysiological mechanisms compromising the cardiac output (3). Over the years, all these concepts were revisited and expanded by adding more variables, like $\mathrm{SvO}_{2}$ and microcirculatory evaluation, explaining the reasons for the reduced peripheral perfusion and setting goals of hemodynamic support for each type of shock (4). The hemodynamic resuscitation and investigation of the cause of the circulatory failure is crucial to prevent organ dysfunction and death.

In order to improve the outcomes of patients with circulatory failure, bedside physicians must be able to make an early recognition of this condition so that individualized management is started. Many educational strategies were developed over time to facilitate teaching and improve understanding of the pathophysiology of shock states, treatment strategies and goals [visual tools (5), mnemonicsSOSD, VIP, ROSE $(4,6)$, etc.]. We agree with Kattan et al. (1) and Messina et al. (2) on the use of different parameters to facilitate the understanding of hemodynamics and we created one single graph (Figure 1) integrating seven variables that are very helpful at the bedside, in order to diagnose the type of shock, interpret hyperlactatemia and suspect of tissue hypoperfusion, and also plan interventions.

When approaching the patient with circulatory shock, evaluating as many variables as possible can help us understand the hemodynamic state and to decide the best treatment. We chose seven hemodynamic data that can give us information about cardiac function, balance of oxygen delivery and consumption, and cellular metabolism, which are important even in settings where invasive monitoring cardiac output is available. Each of these variables can be briefly interpreted as follows:

$\mathrm{ScvO}_{2}$ : Although $\mathrm{ScvO}_{2}$ is not identical to $\mathrm{SvO}_{2}$, particularly in shock situations, it could be used as a substitute for $\mathrm{O}_{2}$ extraction (7). Smaller values would mean larger extractions that are usually present when smaller oxygen supplies occur.

$\mathrm{PCO}_{2}$ gap (7): This gradient is sensitive to blood flow therefore it is elevated in a situation of reduced cardiac output, or as a result of reduced microvascular blood flow and increase in $\mathrm{CO}_{2}$ production due to altered microcirculation (for example: sepsis/septic shock).

Lactate (4): The elevation of lactate may reflect a state of tissue hypoperfusion, however, there are several other causes and interpretations. Among the several causes of hyperlactatemia without hypoperfusion, the most frequent are comorbidities such as cancer and liver diseases, mitochondrial dysfunction (due to genetic diseases), vitamin deficiency (B1) or excessive catecholaminergic release. In these situations, lactate is generally the only altered variable, with no other signs of tissue hypoxia.

CVP (7): Central venous pressure does not adequately identify fluid-responsive patients, however, low values reflect adequate contractile capacity to maintain low pressures of the right atrium. Faced with a state of

^ ORCID: Dimitri Gusmao-Flores: 0000-0002-1973-6099; Mariana Luz: 0000-0003-4679-8655; Bruna Brandão Barreto: 0000-0002-86703270 

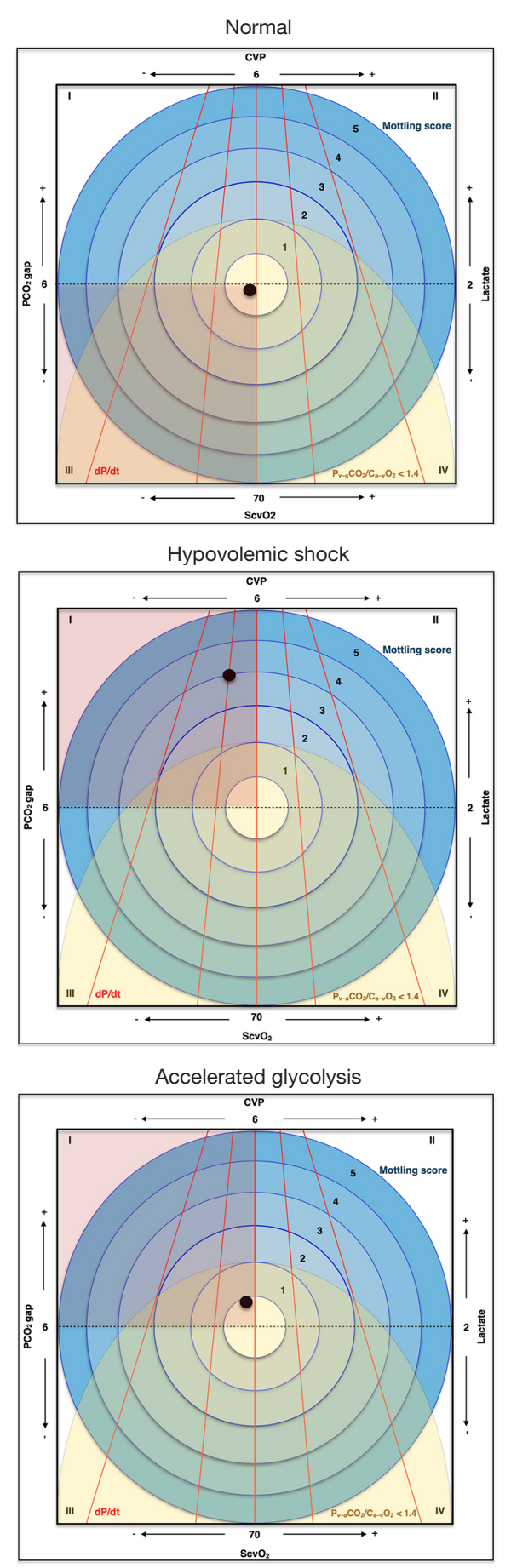
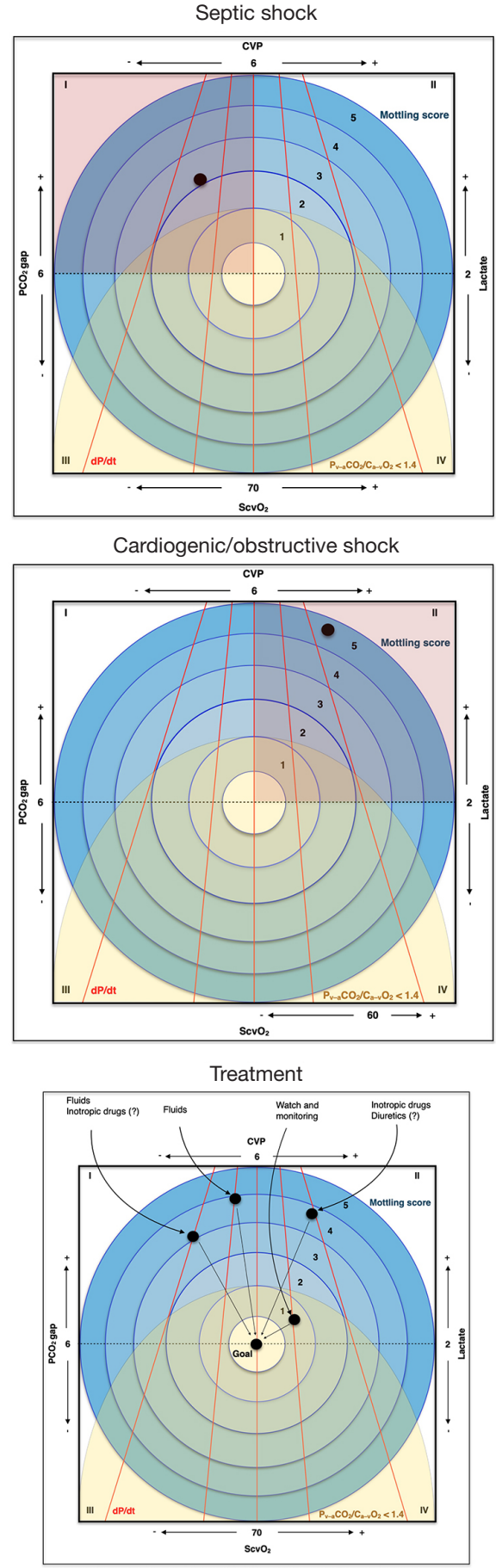

Figure 1 Understanding hemodynamics with seven variables. The $\mathrm{ScvO}_{2}$, Lactate, CVP and $\mathrm{PCO}_{2}$ gap are shown on each side of the square; $\mathrm{dP} / \mathrm{dt}$ is represented by red lines (and the different slopes represent how fast the pressure is reached), the Mottling score is represented by blue circles, each one reflecting a score and the $\mathrm{Pv}-\mathrm{aCO}{ }_{2} / \mathrm{Ca}-\mathrm{vO}_{2}<1.4$ is identified by a yellow semicircle, the points within this area mean a ratio less than 1.4. The position of the black dot represents a clinical presentation of each of the situation described, and in the graph at the bottom right, we presented the change of the hemodynamic parameters after interventions aiming for the resolution of septic shock. $\mathrm{ScvO}_{2}$, oxygen saturation of the central venous blood; $\mathrm{O}_{2}$, oxygen; $\mathrm{PCO}_{2}$ gap, central venous-to-arterial carbon dioxide tension difference; CVP, central venous pressure; $\mathrm{Pv}-\mathrm{aCO} / \mathrm{Ca}-\mathrm{vO}_{2}$, ratio of the venous-to-arterial carbon dioxide tension difference over the arterial-to-venous oxygen content difference; $\mathrm{dP} / \mathrm{dt}$, rate of change in pressure with time. 
circulatory shock, reduced right atrium pressure makes the diagnosis of cardiogenic or obstructive shock unlikely. In selected cases, considering a subjective assessment of the $\mathrm{dP} / \mathrm{dT}$ (below), the use of inotropic could be considered.

$\mathrm{dP} / \mathrm{dt}$ (rate of change in pressure with time): It is a measure that requires echocardiography, however, the assessment of the arterial pulse waveform can be used as surrogate. The greater the contractile capacity of the left ventricle, the greater the $\mathrm{dP} / \mathrm{dt}$. Analyzing the arterial waveform, the maximal first slope of the arterial pulse wave would reflect the contractile capacity: systolic slope closer to 90 degrees means good contractility (peak pressure is achieved in less time) (8).

$\mathrm{P}_{\mathrm{v}-\mathrm{a}} \mathrm{CO}_{2} / \mathrm{C}_{\mathrm{a}-\mathrm{v}} \mathrm{O}_{2}$ : This is a surrogate of the respiratory quotient. Increased values suggest a $\mathrm{CO}_{2}$ production greater than $\mathrm{O}_{2}$ consumption, which may indicate anaerobic metabolism (9). It may also identify patients that, being fluid-responsive, will increase $\mathrm{O}_{2}$ consumption with fluid bolus. Thus, it could help to differentiate hyperlactatemia due to tissue hypoxia (which can benefit from increase in $\mathrm{O}_{2}$ delivery) from hyperlactatemia due to other causes.

Mottling score (10): Cutaneous perfusion depends on cutaneous perfusion pressure, so the presence of mottling suggests hypoperfusion. The higher the mottling score is, the earlier death occur. In situations where there is doubt whether hyperlactatemia is due to oxygen transport deficit, the absence of mottling would reinforce the idea of elevated lactate due to another etiology or at least suggest it can be safe watch and wait until we have more data at hand.

Combining these variables, it is possible to identify different types of shock, to evaluate whether we are facing a situation with clear signs of tissue hypoxia (representing different positions in the graphic-see Figure 1), and to decide the appropriate treatment.

Circulatory shock is a clinical syndrome associated with multi-organ failure and high mortality. Prompt identification of the main pathophysiological mechanism, as well as clinical signs of tissue hypoxia is of extreme importance in order to initiate an immediate and appropriate treatment. Our graph is meant to illustrate the hemodynamic parameters that could help with the diagnostic approach, as well as to plan interventions. However, there is often an overlap between different types of shock which may make interpretation of the etiology more difficult even using several integrated variables.

The use of graphs and figures to help understanding the circulatory dynamics of shock syndromes is not new. In 1987, Shoemaker used a four-sided figure representing the four dimensions that characterize fluid systems (pressure, volume, flow and function-which is best characterized by oxygen consumption) in order to explain the pathophysiology of different types of circulatory failure (5). Similarly, the presented graph can be useful as an educational tool, especially in teaching units and residency programs.

\section{Acknowledgments}

Funding: None.

\section{Footnote}

Provenance and Peer Review: This article was a free submission to the journal. The article did not undergo external peer review.

Conflicts of Interest: All authors have completed the ICMJE uniform disclosure form (available at http://dx.doi. org/10.21037/atm-20-5493). The authors have no conflicts of interest to declare.

Ethical Statement: The authors are accountable for all aspects of the work in ensuring that questions related to the accuracy or integrity of any part of the work are appropriately investigated and resolved.

Open Access Statement: This is an Open Access article distributed in accordance with the Creative Commons Attribution-NonCommercial-NoDerivs 4.0 International License (CC BY-NC-ND 4.0), which permits the noncommercial replication and distribution of the article with the strict proviso that no changes or edits are made and the original work is properly cited (including links to both the formal publication through the relevant DOI and the license). See: https://creativecommons.org/licenses/by-nc-nd/4.0/.

\section{References}

1. Kattan E, Castro R, Vera M, et al. Optimal target in septic shock resuscitation. Ann Transl Med 2020;8:789.

2. Messina A, Collino F, Cecconi M. Fluid administration for acute circulatory dysfunction using basic monitoring. Ann Transl Med 2020;8:788.

3. Weil MH, Shubin H. Proposed reclassification of shock states with special reference to distributive defects. Adv Exp Med Biol 1971;23:13-23. 
4. Vincent JL, De Backer D. Circulatory shock. N Engl J Med 2013;369:1726-34.

5. Shoemaker WC. Relation of oxygen transport patterns to the pathophysiology and therapy of shock states. Intensive Care Med 1987;13:230-43.

6. Malbrain ML, Van Regenmortel N, Saugel B, et al. Principles of fluid management and stewardship in septic shock: it is time to consider the four D's and the four phases of fluid therapy. Ann Intensive Care 2018;8:66.

7. Cecconi M, De Backer D, Antonelli M, et al. Consensus on circulatory shock and hemodynamic monitoring. Task force of the European Society of Intensive Care Medicine.
Intensive Care Med 2014;40:1795-815.

8. Tartiere JM, Tabet JY, Logeart D, et al. Noninvasively determined radial $\mathrm{dP} / \mathrm{dt}$ is a predictor of mortality in patients with heart failure. Am Heart J 2008;155:758-63.

9. Mekontso-Dessap A, Castelain V, Anguel N, et al. Combination of venoarterial PCO2 difference with arteriovenous $\mathrm{O} 2$ content difference to detect anaerobic metabolism in patients. Intensive Care Med 2002;28:272-7.

10. Ait-Oufella H, Lemoinne S, Boelle PY, et al. Mottling score predicts survival in septic shock. Intensive Care Med 2011;37:801-7.

Cite this article as: Gusmao-Flores D, Luz M, Barreto BB. Understanding hemodynamics with seven variables. Ann Transl Med 2020;8(20):1332. doi: 10.21037/atm-20-5493 